\title{
Association Between Estrus Cycle-Related Changes in Respiration and Estrus Cycle-Related Aggression in Outbred Female Wistar Rats
}

\author{
Marie Olsson*,', Hoi-Por Ho', Kristina Annerbrink', Lydia K Melchior', Jan Hedner² and Elias Eriksson' \\ 'Department of Pharmacology, Göteborg University, Göteborg, Sweden; Department of Clinical Pharmacology, Göteborg University, Göteborg, \\ Sweden
}

\begin{abstract}
Premenstrual dysphoric disorder is characterized by irritability surfacing during the luteal phase of the menstrual cycle, and disappearing shortly after the onset of menstruation. Although the cardinal symptoms of premenstrual dysphoria are different from those of panic disorder, the two conditions share a number of traits indicating that they both may be associated with abnormalities in the regulation of respiration. Both subjects with panic disorder and subjects with premenstrual dysphoria are hence reported to display enhanced respiratory variability, and to experience anxiety when exposed to $\mathrm{CO}_{2}$. In the present study, the possible influence of the estrus cycle on respiratory parameters in outbred female rats of the Wistar strain was investigated. Before being tested with respect to respiration, the rats were subdivided into two groups: those displaying estrus cycle-related variation in aggression, as evaluated using the resident intruder paradigm, and those not showing aggression throughout the cycle. Whereas the former group was found to display higher respiratory rate during the diestrus phase than during the proestrus/estrus phase, no cycle-related variation in respiration was observed in animals not showing cycle-related variation in aggression. The results support previous studies indicating that the estrus cycle exerts an influence on respiration, and suggest that rats prone to cycle-related aggression are more sensitive also to the influence of hormonal cyclicity on respiration. The possible bearing of these findings for the aberration in respiration displayed by subjects with premenstrual dysphoria is discussed.
\end{abstract}

Neuropsychopharmacology (2003) 28, 704-710. doi:I0.1038/sj.npp. 1300074

Keywords: aggression; estrus cycle; premenstrual dysphoria; respiration; $\mathrm{CO}_{2}$; rat

\section{INTRODUCTION}

A severe form of premenstrual dysphoria afflicts about 5\% of women of fertile age and is characterized by a constellation of symptoms appearing regularly in the luteal phase of the menstrual cycle, and disappearing within a few days after the onset of bleeding (American Psychiatric Association, 1994). Irritability and anger are cardinal symptoms, but sadness, affect lability, and tension also are common complaints (Eriksson, 1999; Freeman and Halbreich, 1998; Steiner, 1997). The importance of female sex steroids for premenstrual dysphoria is illustrated not only by the fact that the symptoms are cycle dependent, but also by the observations that they are alleviated by ovariectomy and menopause, and can be made to reappear

* Correspondence: Dr M Olsson, Department of Pharmacology, Göteborg University, Box 43I, SE 40530 Göteborg, Sweden, Tel: +46 31 77334 48, Fax: +46 31 8210 85, E-mail: marie.olsson@pharm.gu.se Received 27 March 2002; revised 6 September 2002; accepted 9 September 2002

Online publication: 25 September 2002 at http://www.acnp.org/ citations/Npp09250239| by the administration of exogenous female sex steroids (see Eriksson et al, 2000).

Recent studies suggest that premenstrual dysphoria is characterized by aberrations in respiration; as compared to normal controls, women with premenstrual dysphoria thus display an increase in respiratory variability (Martinez et al, 2001) as well as enhanced anxiety when exposed to $\mathrm{CO}_{2}$ (Harrison et al, 1989; Kent et al, 2001). In these regards, patients with premenstrual dysphoria show striking similarity with patients with panic disorder, a condition also characterized by enhanced respiratory variability (see Martinez et al, 2001) and increased responsiveness to $\mathrm{CO}_{2}$ (Gorman et al, 1984; Kent et al, 2001; Klein, 1993; Papp et al, 1997). Another similarity between panic disorder and premenstrual dysphoria is that both conditions respond to treatment with serotonin reuptake inhibitors (Boyer, 1995; Den Boer and Westenberg, 1988; Eriksson et al, 1995; Modigh et al, 1992; Perna et al, 2001; Sasson et al, 1999; Steiner et al, 1995; Sundblad et al, 1992; Wikander et al, 1998; Yonkers, 1997), including clomipramine administered at very low dosage (Caillard et al, 1999; Gloger et al, 1989; Sundblad et al, 1993). 
Cycle-dependent irritability and aggression-as displayed by women with premenstrual dysphoria - may be observed also in nonhuman species, such as rat (Swanson et al, 1982), dairy cows and heifers (Castellanos et al, 1992), and vervet monkeys (Rapkin et al, 1995). We recently reported that approximately $40 \%$ of outbred female Wistar rats display aggressive behavior in the nonreceptive phases - metestrus and diestrus - but not in the receptive phases - proestrus and estrus - of the 4-day estrus cycle (Ho et al, 2001). The metestrus and diestrus phases, in which aggressive behavior occurs, roughly correspond to the premenstrual phase of the human menstrual cycle, in that they follow ovulation and a peak in progesterone levels, and that they are characterized by low probability of conception.

Previous studies have shown that women with premenstrual dysphoria experience symptom relief when treated with an ovulation inhibitor, but a return of symptoms when exposed to exogenous female sex steroids; in contrast, women with no history of premenstrual dysphoria experience no symptoms when exposed to exogenous sex steroids after inhibition of ovulation (Rubinow et al, 1998). In close parallel with these findings, we observed that the aggressive behavior in Wistar rats displaying estrus cycle-related aggression at baseline can be abolished by means of ovariectomy and reinstated by administration of estrogen plus progesterone; rats displaying no aggressive behavior at baseline however also do not display aggression when exposed to exogenous sex steroids (after ovariectomy) (Ho et al, 2001). This observation - as well as the finding that estrus-related aggression in female Wistar rats can be effectively reduced by treatment with a serotonin reuptake inhibitor - has prompted us to suggest that this may serve as an animal model reflecting mechanisms of relevance for premenstrual dysphoria in humans (Ho et al, 2001).

The main purpose of this study was to test the hypothesis that respiratory parameters such as baseline respiratory rate, baseline tidal volume, and $\mathrm{CO}_{2}$-induced hyperventilation are dependent on estrus cycle phase in outbred female Wistar rats. Prompted by our earlier findings that some (but not all) female Wistar rats display cycle-dependent aggression, and by the apparent relation between cycle-related irritability and respiratory abnormalities in humans, a second purpose was to explore to what extent rats displaying cycle-related aggression differ from rats of the same strain not displaying cycle-related aggression with respect to respiration in different phases of the estrus cycle.

\section{MATERIALS AND METHODS}

\section{Ethics}

The study was carried out in accordance with the Guide for the Care and Use of Laboratory Animals as adopted and promulgated by the $\mathrm{NIH}$, and was approved by the Ethics Committee for Animal Experiments, Göteborg University, Sweden.

\section{Rats}

Rats weighing 280-300 g were obtained from B\&K (Sollentuna, Sweden), and housed in cages with three rats per cage under controlled conditions: temperature $21-22^{\circ} \mathrm{C}$, humidity 55-65\%, and reversed 12/12 h light/dark cycle. Food and water were available ad libitum at all times except during the experiments.

\section{Estrus Cycle Phases}

Estrus cycle phases were determined by assessment of estrus behavior (hop/darting, ear wiggling, lordosis) when placing the female rat in a cage with three male rats, and stroking her on the back (Kow, 1976; Sodersten and Eneroth, 1981). The male rats were prevented from mounting the female rat. Rats were considered to be in the proestrus/estrus phase (= receptive phase) when displaying estrus behavior, and to be in the diestrus phase (= nonreceptive phase) 2 days later. Only rats displaying regular cyclicity were used in the experiments.

\section{Resident Intruder Tests}

Female rats $(n=45)$ were housed in cages for more than a month to establish the home cage as their own territory. Tests of aggression were performed 2 days after the rats displayed estrus behavior, that is, when the rats were in the diestrus phase, and took place between $10 \mathrm{am}$ and $4 \mathrm{pm}$ in the same room as the rats were normally kept. The home cage was placed on a table, lit by dim white light $(<2 \mathrm{~lx})$, and the rats, except the one being tested, were removed from the cage. After a habituation time of about $15 \mathrm{~min}$, an ovariectomized female intruder was introduced into the cage for a period of $10 \mathrm{~min}$. During this period, an observer scored various aspects of aggression - attacks, attack-time, bites, on-top, and on-top time-displayed by the resident. The attacks were of two types, lunge attacks (jumping at the intruder to topple it down) and lateral attacks (on toes with arched back, moving sideways against the intruder to push it over). The rats were considered aggressive if they displayed bite and/or lateral attack in two separate tests. If a rat did not display aggressive behavior in neither test it was considered nonaggressive.

\section{Respiration Experiments}

Respiration experiments were performed on 30 freely moving female Wistar rats, 15 of which displayed cyclerelated aggressive behavior in the resident intruder paradigm, and 15 not displaying aggression in this test. Experiments were performed during both the diestrus and the proestrus/estrus phase.

The plethysmograph used to monitor ventilation was made of Plexiglas and cylindrical in shape (height $235 \mathrm{~mm}$, diameter $290 \mathrm{~mm}$, volume $15.5 \mathrm{l}$ ). The animals were able to move freely inside the plethysmograph. A sensor membrane, responding to pressure differences in the plethysmograph caused by the animal breathing, was connected to a Macintosh computer (software: MacLab) via a transducer. Respiratory rate (breaths per $\min =\mathrm{BPM}$ ), tidal volume ( $\mathrm{ml} /$ breath), and minute volume $(\mathrm{ml} / \mathrm{min})$ were registered. The equipment was calibrated with a known volume before experiments.

The gas used was either $100 \% \mathrm{CO}_{2}$ or a control gas consisting of pure room air $\left(20 \% \mathrm{O}_{2}+80 \% \mathrm{~N}_{2}\right)$ (Air Liquide, 
Göteborg, Sweden). $\mathrm{CO}_{2}$ was allowed to mix with pure room air in order to obtain a $\mathrm{CO}_{2}$ level of $2 \%$. The gas was administered through a valve in the plethysmograph, with a constant inflow rate of approximately $31 / \mathrm{min}$, regulated by a BS300 regulator and a Dynamal inflow-rate meter (Air Liquide, Göteborg, Sweden). Another valve was used for pressure monitoring. A 2001 VTCM gas meter (ComfortControl, Uppsala, Sweden) was used to measure the level of $\mathrm{CO}_{2}$ as well as the temperature within the plethysmograph.

All respiration experiments took place in a silent room with the lights on and an observer placed approximately $1 \mathrm{~m}$ from the rat. Before respiratory measurement, the animals were habituated to the plethysmograph on three separate days $(20 \mathrm{~min}+20 \mathrm{~min}+20 \mathrm{~min})$. At the time of the experiment, the rat was transferred from its home cage to the plethysmograph. The experiments were performed between 9 am and $6 \mathrm{pm}$, that is, during the period when the animal was awake. After a habituation period of 10-12 $\mathrm{min}, 2 \mathrm{~min}$ of consecutive baseline registrations were obtained. Thereafter, either $\mathrm{CO}_{2}$ or control gas was administered, followed by a 2-3 min period, during which the rat returned to a resting state, before another $2 \mathrm{~min}$ of consecutive respiratory registration were obtained.

The gross activity of the animal was rated during the experiment. Registrations were only undertaken in nonmoving animals in order to avoid artifactual readings. If the animal moved at the end of the habituation period or during data collection, it was retested another day. No rats were asleep during the respiratory measurements. Rats were given no more than three trials to qualify for respiratory measurements in each cycle phase with $\mathrm{CO}_{2}$ and control gas, respectively. No rat was exposed to gas more than once per day. Baseline registrations obtained before disqualification owing to the animal moving after gas administration were used in the subsequent analyses of baseline respiration. The rate of respiration experiments being excluded from analysis owing to the animal moving at baseline recording or after $\mathrm{CO}_{2}$ exposure was approximately $20 \%$, and did not differ between aggressive and nonaggressive rats.

Rats were administered $2 \% \mathrm{CO}_{2}$ and control gas in the proestrus/estrus and the diestrus phase of the cycle at random order; thus, two baseline registrations during each cycle phase were obtained. Since some rats were disqualified from respiratory assessment because of reasons mentioned above, and others stopped displaying regulatory estrus cycles during the course of the study, the numbers of rats studied in proestrus/estrus and diestrus, respectively, are not identical. In order to reduce intraindividual variability, as a measure of baseline respiratory rate in each phase of the cycle, the mean value of the two baseline registrations obtained in the same phase was used.

\section{Locomotor Test}

Assessment of locomotor activity in a novel environment was undertaken in a subgroup of aggressive and nonaggressive rats, respectively, using soundproof and ventilated activity boxes with a floor area of $700 \times 700 \mathrm{~mm}^{2}$. These boxes were equipped with two rows of photocells, and were connected to a computer (box and software from Kungsbacka Mät-och Reglerteknik AB, Fjärås, Sweden). Locomotor activity was assessed by registration of the breaking of a sequence of beams, representing movement in a single direction, and was expressed as counts $/ 5 \mathrm{~min}$. Animals were not habituated to the activity boxes before being tested. The test lasted for $60 \mathrm{~min}$ and was undertaken in both the proestrus/estrus and diestrus phase of the cycle, at random order.

\section{Statistical Analysis}

Differences between groups in the respiration experiments were evaluated statistically using ANOVA; for a post hoc comparison of different groups, Fisher's PLSD test was used. In addition, two-way ANOVAs with group (aggressive $v s$ nonaggressive) and phase (proestrus/estrus $v s$ diestrus) as factors were performed. Data obtained in the locomotor activity experiment also were analyzed using two-way ANOVAs, with time $v s$ cycle phase or time $v s$ group (aggressive $v s$ nonaggressive) as factors. All statistical analyses were two tailed. Values are expressed as mean ( $\pm \mathrm{SD}) ; p \leqslant 0.05$ was considered statistically significant. When analyzing the response to gas inhalation, both delta differences (mean value after gas administration minus mean value before gas administration, expressed as delta respiratory rate, delta tidal volume, and delta minute volume), and mean values reached after gas administration, were considered.

\section{RESULTS}

\section{Baseline Ventilation}

When all rats were analyzed as one group, the mean baseline respiratory rate was found to be higher during the diestrus phase of the cycle $(106.5 \pm 13.2 \mathrm{BPM}, n=27)$ compared to the proestrus/estrus phase $(97.2 \pm 10.1 \mathrm{BPM}$, $n=19)(p=0.01)$. In contrast, no significant effect of cycle phase on tidal volume or minute volume was observed (data not shown).

When aggressive and nonaggressive rats were analyzed separately, the relation between respiratory rate and estrus cycle was found to reside within the group of rats displaying cycle-related aggression only; nonaggressive rats thus did not display any fluctuation in respiratory rate during the estrus cycle. In aggressive rats, both respiratory rate and minute volume was significantly higher during the diestrus phase than during proestrus/estrus (Table 1).

When aggressive and nonaggressive rats were compared, aggressive rats were found to display lower baseline respiratory rate, but not minute volume or tidal volume, in the proestrus/estrus phase compared to nonaggressive rats. Differences between groups during the diestrus phase did not reach statistical significance (Table 1).

In line with the results presented above, a two-way ANOVA regarding baseline respiratory rate revealed no significant effect of group (aggressive $v s$ nonaggressive rats) $(p=0.3)$ but a significant effect of phase (proestrus/estrus $v s$ diestrus $)(p=0.005)$ and a significant phase ${ }^{\star}$ group interaction $(p=0.02)$. Two-way ANOVAs for baseline tidal volume and minute volume did not reveal any significant effect of group or phase.

The finding that rats displaying cycle-related aggression, as opposed to nonaggressive rats, display higher respiratory rate in the diestrus phase than in the proestrus/estrus phase 
Table I Baseline Respiration in Aggressive and Nonaggressive rats During Different Phases of the Estrus Cycle

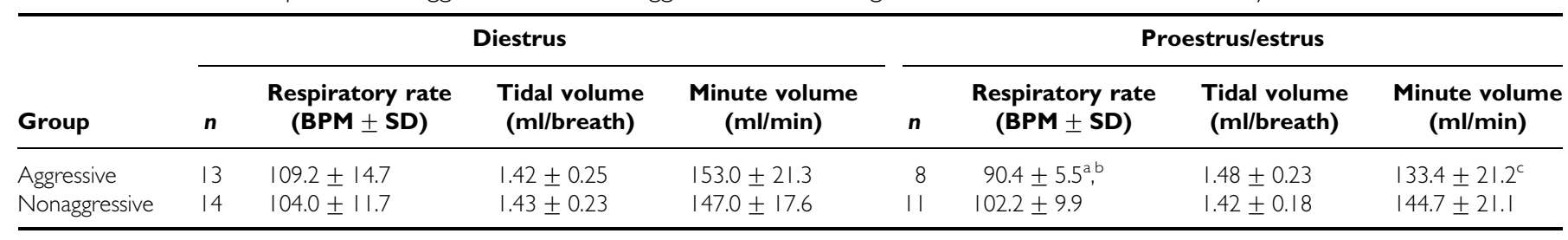

${ }^{a} p=0.003$ as compared to aggressive rats in the diestrus phase (ANOVA followed by Fisher's PLSD test).

${ }^{b} p=0.007$ as compared to nonaggressive rats in the proestrus/estrus phase (ANOVA followed by Fisher's PLSD test)

$c^{c} p=0.05$ as compared to aggressive rats in the diestrus phase (ANOVA followed by Fisher's PLSD test).

Table 2 Effects of $\mathrm{CO}_{2}$ Inhalation on Respiration in Aggressive and Nonaggressive Rats During Different Phases of the Estrus Cycle

\begin{tabular}{|c|c|c|c|c|c|c|c|c|}
\hline Group & \multicolumn{4}{|c|}{ Diestrus } & \multicolumn{4}{|c|}{ Proestrus/estrus } \\
\hline Aggressive & $1 \overline{2}$ & $112.6 \pm 16.8$ & $136.5 \pm 19.4$ & $23.9 \pm 12.0$ & 6 & $93.6 \pm 8.6^{\mathrm{a}}$ & $123.2 \pm 6.9$ & $29.6 \pm 4.6$ \\
\hline Nonaggressive & 13 & $103.3 \pm 15.6$ & $128.4 \pm 20.5$ & $25.0 \pm 14.1$ & 9 & $102.5 \pm 17.1$ & $1 \mid 4.9 \pm 14.3$ & $12.5 \pm 13.0^{b}$ \\
\hline \multicolumn{9}{|c|}{ (b) Tidal volume (ml/breath $\pm S D)$} \\
\hline \multicolumn{9}{|c|}{ (c) Minute volume $(\mathrm{ml} / \mathrm{min} \pm \mathrm{SD})$} \\
\hline Aggressive & 12 & $160.8 \pm 21.0$ & $182.9 \pm 28.5$ & $22.1 \pm 19.4$ & 6 & $|4| .8 \pm 36.6$ & $163.0 \pm 45.6$ & $21.2 \pm 11.6$ \\
\hline Nonaggressive & 13 & $150.5 \pm 20.1$ & $169.8 \pm 10.0$ & $19.4 \pm 18.2$ & 9 & $145.5 \pm 29.6$ & $163.2 \pm 29.3$ & $17.3 \pm 10.3$ \\
\hline
\end{tabular}

${ }^{a} p=0.02$ as compared to aggressive rats in the diestrus phase (ANOVA followed by Fisher's PLSD test).

${ }^{b} p=0.05$ as compared to nonaggressive rats in the diestrus phase (ANOVA followed by Fisher's PLSD test).

$c_{p}=0.009$ as compared to aggressive rats in the proestrus/estrus phase (ANOVA followed by Fisher's PLSD test).

was confirmed in an independent experiment using Wistar rats from a different batch (data not shown).

\section{$\mathrm{CO}_{2}$ Inhalation}

In both aggressive rats and nonaggressive rats, exposure to $\mathrm{CO}_{2}$, as compared to exposure to control gas, led to a significant increase in respiratory rate $(p<0.0001)$ and minute volume $(p=0.001)$, but not in tidal volume $(p=0.5)$.

The respiratory rate observed after $\mathrm{CO}_{2}$ - but neither the tidal volume nor the minute volume - was higher in the diestrus phase $(132.4 \pm 20.0 \mathrm{BPM} ; n=25)$ than in the proestrus/estrus phase $(118.2 \pm 12.3 \mathrm{BPM} ; \quad n=15)$ $(p=0.02)$; this difference was observed in both aggressive and nonaggressive rats (Table 2), but it reached statistical significance only when all rats were analyzed as one group. The $\mathrm{CO}_{2}$ induced increase in respiratory rate (delta values) - but neither in tidal volume nor in minute volume - was significantly higher in the diestrus phase than in the proestrus/estrus phase in nonaggressive rats, but not in aggressive animals because of low baseline during estrus (Table 2).

A comparison of aggressive and nonaggressive rats revealed no differences with respect to respiratory rate, tidal volume, or minute volume following $\mathrm{CO}_{2}$. The delta increase in respiratory rate however was significantly higher in aggressive rats than in nonaggressive rats in the proestrus/estrus phase (Table 2a), because of lower levels at baseline. $\mathrm{CO}_{2}$-induced changes in tidal volume and minute volume never differed between aggressive and nonaggressive rats.

In line with the results presented above, a two-way ANOVA regarding respiratory rate during $\mathrm{CO}_{2}$ inhalation revealed a significant effect of phase (proestrus/estrus $v s$ diestrus) $(p=0.03)$, but no significant effect of group (aggressive $v s$ nonaggressive rats) $(p=0.2)$, and no significant phase ${ }^{\star}$ group interaction $(p=1)$. A two-way ANOVA regarding the increase in respiratory rate (delta values) did not show a significant effect of phase $(p=0.4)$ but borderline significant effect of group $(p=0.06)$ and a significant phase ${ }^{\star}$ group interaction $(p=0.03)$. The two-way ANOVAs regarding tidal volume, delta tidal volume, minute volume, and delta minute volume did not reveal any significant effects of group or phase.

\section{Locomotor Test}

All groups of rats displayed a pattern of locomotion typical of animals put in a novel environment, with high exploratory activity initially, decreasing to baseline within $20 \mathrm{~min}$. Total counts during the $60 \mathrm{~min}$ period for aggressive rats were $478 \pm 122 \quad(n=8) \quad$ (proestrus/estrus) and $430 \pm 181(n=8)$ (diestrus), respectively, and for nonaggressive rats $472 \pm 53 \quad(n=5)$ (proestrus/estrus) and $494 \pm 100 \quad(n=5) \quad$ (diestrus), respectively. A two-way ANOVA revealed a significant effect of time $(p<0.0001)$ but no effect of group (aggressive/nonaggressive) (in any of the two phases) and also no effect of cycle phase (either in aggressive or nonaggressive animals). 


\section{DISCUSSION}

One purpose of this study was to examine the hypothesis that respiratory parameters are influenced by the estrus cycle in a batch of outbred, female, freely moving Wistar rats. Whereas tidal volume did not appear to be phase dependent, a clearcut increase in respiratory rate was observed during the diestrus phase-that is, the phase approximately corresponding to the luteal, premenstrual phase in humans - as compared to the proestrus/estrus phase.

To our knowledge, this is the first study reporting an influence of the estrus cycle on respiratory rate in freely moving rats. Our observation however is to some extent in line with the notion that progesterone is a respiratory stimulant per se, as well in conjunction with estrogen (Tatsumi et al, 1995), and with clinical studies suggesting higher minute volume in women than in men (Loeppky et al, 2001), and higher minute volume during pregnancy (Tatsumi and Hannhart, 1995). A number of previous clinical studies also suggest that the minute volume is higher in the luteal phase than in the follicular phase (Dutton et al, 1989), but this difference may at least partly be because of differences in tidal volume rather than in respiratory rate (Das, 1998).

We have previously shown that some (but not all) outbred Wistar rats display a clearcut cyclicity with respect to aggressive behavior, demonstrating marked aggressive behavior during diestrus and metestrus, but no aggressive behavior during proestrus/estrus (see Introduction). Given the fact that respiratory abnormalities have been reported in women displaying menstrual cycle-related dysphoria (Martinez et al, 2001), we deemed it of interest to examine to what extent rats displaying aggressive behavior during the diestrus phase are more prone to display increased ventilation during this phase of the cycle than nonaggressive rats. Indeed this seemed to be the case; when splitting the group of animals into those displaying cycle-related aggression or not, we found that the cycle-related variation in respiratory rate could be attributed entirely to the animals also displaying enhanced aggression during the diestrus phase. Aggressive rats appeared to display both somewhat higher respiratory rate during diestrus and lower respiratory rate during proestrus/estrus as compared to nonaggressive rats, but only the latter difference was statistically significant.

To assess the possibility that the cyclicity with respect to both respiration and aggression in aggressive rats was secondary to cyclicity with respect to general activity, we also measured locomotor activity (including exploratory behavior) in a subgroup of aggressive and nonaggressive rats, respectively, during the different phases of the cycle. These experiments however lend no support for any major difference between the two groups of animals with respect to locomotion, and also no support for an influence of the estrus cycle on this parameter. It should however be underlined that a lack of influence of the cycle on the motor activity in these experiments - reflecting both baseline locomotion and exploration/habituation-does not exclude that such an influence could be of importance in a different experimental setting, as indicated by previous studies examining the influence of cycle phase on motor activity such as wheel running (Finger, 1969; Jennings, 1969; Steiner et al, 1981). Indeed, inspection of the gross behavior of the animals in their home cage did suggest a somewhat higher activity during the proestrus/estrus phase in both aggressive and nonaggressive rats (unpublished observation); this difference is however not likely to be of importance for differences in respiratory parameters, since rats that were moving during registration of respiration were excluded.

The reason for rats displaying cycle-related variation in aggression also displaying cycle-related variation in respiration - but not in general activity - is not obvious, but may tentatively be related to the finding that women with premenstrual dysphoria report abnormalities with respect to respiration, similar to those observed in panic disorder. Notably, female sex steroids influence both respiration and aggressive behavior, progesterone tentatively stimulating both parameters; it may hence be speculated that an enhanced responsiveness to sex steroids, or relatively marked fluctuations in serum levels of these hormones, could result in an increased influence of cyclicity on both respiration and aggression. Of interest in this context is the finding that sex steroids seem to be of importance not only for premenstrual dysphoria, but also for panic disorder; this disorder is twice as common in women as in men (Yonkers et al, 1998), and there are studies suggesting that panic attacks may exacerbate premenstrually (Basoglu et al, 2000; Breier et al, 1986; Cameron et al, 1988; Cook et al, 1990; Klein, 1993) and improve during pregnancy (Hertzberg and Wahlbeck, 1999; Klein et al, 1994; Villeponteaux et al, 1992).

Notably, the brain neurotransmitter serotonin exerts a profound influence on respiration (see McCrimmon et al, 1995) as well as on aggression (see De Cuyper, 1987; Eriksson and Humble, 1990). Serotonin reuptake inhibitors thus effectively normalize both enhanced responsiveness to $\mathrm{CO}_{2}$ in patients with panic disorder and cycle-related irritability in women with premenstrual dysphoric disorder, and these compounds also have been found to influence both cycle-related irritability (Ho et al, 2001) and respiratory rate in Wistar rats (Olsson et al, unpublished). The possibility that differences in brain serotonergic transmission may explain why some, but not all, rats display cyclical variation in both aggression and respiration is therefore worth considering.

In line with earlier studies showing an increase in $\mathrm{CO}_{2}$ sensitivity in the luteal phase of the menstrual cycle as compared to the follicular phase in humans (Dutton et al, 1989), the rats reached significantly higher respiratory rate after $\mathrm{CO}_{2}$ inhalation during the diestrus phase of the estrus cycle than during the proestrus/estrus phase. Since this influence of cycle phase on the response to $\mathrm{CO}_{2}$ was observed in both aggressive and nonaggressive rats, this experiment however lends no support for the assumption that the difference between these groups with respect to baseline respiratory rate is because of differences in $\mathrm{CO}_{2}$ responsiveness. Although a difference in chemoreceptor sensitivity nevertheless cannot be excluded, other explanations to the difference in baseline respiratory rate should thus be considered.

The findings that nonaggressive but not aggressive rats displayed significantly higher delta response to $\mathrm{CO}_{2}$ during diestrus than during proestrus/estrus, and the difference in 
delta response to $\mathrm{CO}_{2}$ between nonaggressive and aggressive rats in the proestrus/estrus phase, were apparently because of the low baseline respiratory rate in aggressive rats during the proestrus/estrus phase. Therefore, these findings should probably not be interpreted in terms of differences between the two groups with respect to $\mathrm{CO}_{2}$ responsiveness.

In conclusion, the results suggest that baseline respiration in female rats is dependent on cycle phase, respiratory rate - but not tidal volume - being higher in the phase of the cycle approximately corresponding to the premenstrual phase in women. The observation that this influence of the estrus cycle is observed only in animals displaying a cyclerelated variation in aggression in a putative animal model of premenstrual dysphoria may tentatively correspond to the finding that cycle-related irritability in women seems to be associated with abnormalities in respiration. $\mathrm{CO}_{2}$ responsiveness appeared to be higher in the diestrus phase than in the proestrus/estrus phase, but in this regard aggressive and nonaggressive rats did not differ from each other.

\section{ACKNOWLEDGEMENTS}

This study was sponsored by the Swedish Medical Research Council (Grant No. 8668), Astra Zeneca, Thuring's Foundation, Wallenberg's Foundation, Lundberg's Foundation, and the Swedish Lundbeck Foundation. Ms Inger Oscarsson and Ms Gunilla Bourghardt provided excellent technical assistance.

\section{REFERENCES}

American Psychiatric Association (1994). Diagnostic and Statistical Manual of Mental Disorders, 4th edn. APA Press: Washington, DC.

Basoglu C, Cetin M, Semiz UB, Agargun MY, Ebrinc S (2000). Premenstrual exacerbation and suicidal behavior in patients with panic disorder. Compr Psychiatry 41: 103-105.

Boyer W (1995). Serotonin uptake inhibitors are superior to imipramine and alprazolam in alleviating panic attacks: a metaanalysis. Int Clin Psychopharmacol 10: 45-49.

Breier A, Charney DS, Heninger GR (1986). Agoraphobia with panic attacks. Development, diagnostic stability, and course of illness. Arch Gen Psychiatry 43: 1029-1036.

Caillard V, Rouillon F, Viel JF, Markabi S (1999). Comparative effects of low and high doses of clomipramine and placebo in panic disorder: a double-blind controlled study. French University Antidepressant Group. Acta Psychiatr Scand 99: 51-58.

Cameron OG, Kuttesch D, McPhee K, Curtis GC (1988). Menstrual fluctuation in the symptoms of panic anxiety. J Affect Disord 15: 169-174.

Castellanos F, Orihuela A, Galina CS (1992). Aggressive behaviour in oestrus and dioestrus dairy cows and heifers. Vet Rec 131: 515.

Cook BL, Noyes Jr R, Garvey MJ, Beach V, Sobotka J, Chaudhry D (1990). Anxiety and the menstrual cycle in panic disorder. $J$ Affect Disord 19: 221-226.

Das TK (1998). Effects of the menstrual cycle on timing and depth of breathing at rest. Indian J Physiol Pharmacol 42: 498-502.

De Cuyper H (1987). (Auto)aggression and serotonin. A review of human data. Acta Psychiatr Belg 87: 325-331.

Den Boer JA, Westenberg HG (1988). Effect of a serotonin and noradrenaline uptake inhibitor in panic disorder; a double-blind comparative study with fluvoxamine and maprotiline. Int Clin Psychopharmacol 3: 59-74.
Dutton K, Blanksby BA, Morton AR (1989). $\mathrm{CO}_{2}$ sensitivity changes during the menstrual cycle. J Appl Physiol 67: 517-522.

Eriksson E (1999). Serotonin reuptake inhibitors for the treatment of premenstrual dysphoria. Int Clin Psychopharmacol 14(Suppl. 1): $\mathrm{S} 27-\mathrm{S} 33$.

Eriksson E, Hedberg MA, Andersch B, Sundblad C (1995). The serotonin reuptake inhibitor paroxetin is superior to the noradrenaline reuptake inhibitor maprotiline in the treatment of premenstrual syndrome. Neuropsychopharmacology 12: 167176.

Eriksson E, Humble M (1990). Serotonin in psychiatric pathophysiology. A review of data from experimental and clinical research. In: Pohl R, Gershon S (eds). The Biological Basis of Treatment, Progress in Basic Clinical Pharmacology. Karger: Basel. pp 66-11.

Eriksson E, Sundblad C, Yonkers KA, Steiner M (2000). Premenstrual dysphoria and related conditions: symptoms, pathophysiology and treatment. In: Steiner M, Yonkers KA, Eriksson, E (eds). Mood Disorders in Women. Martin Dunitz: London.

Finger FW (1969). Estrus and general activity in the rat. J Comp Physiol Psychol 68: 461-466.

Freeman EW, Halbreich U (1998). Premenstrual syndromes. Psychopharmacol Bull 34: 291-295.

Gloger S, Grunhaus L, Gladic D, O'Ryan F, Cohen L, Codner S (1989). Panic attacks and agoraphobia: low dose clomipramine treatment. J Clin Psychopharmacol 9: 28-32.

Gorman JM, Askanazi J, Liebowitz MR, Fyer AJ, Stein J, Kinney JM et al (1984). Response to hyperventilation in a group of patients with panic disorder. Am J Psychiatry 141: 857-861.

Harrison WM, Sandberg D, Gorman JM, Fyer M, Nee J, Uy J et al (1989). Provocation of panic with carbon dioxide inhalation in patients with premenstrual dysphoria. Psychiatry Res 27: 183192.

Hertzberg T, Wahlbeck K (1999). The impact of pregnancy and puerperium on panic disorder: a review. J Psychosom Obstet Gynaecol 20: 59-64.

Ho HP, Olsson M, Westberg L, Melke J, Eriksson E (2001). The serotonin reuptake inhibitor fluoxetine reduces sex steroidrelated aggression in female rats: an animal model of premenstrual irritability? Neuropsychopharmacology 24: 502510.

Jennings WA (1969). Voluntary running and the estrous variation in food intake in the rat. Psychol Rep 25: 199-203.

Kent JM, Papp LA, Martinez JM, Browne ST, Coplan JD, Klein DF et al (2001). Specificity of panic response to $\operatorname{CO}(2)$ inhalation in panic disorder: a comparison with major depression and premenstrual dysphoric disorder. Am J Psychiatry 158: $58-67$.

Klein DF (1993). False suffocation alarms, spontaneous panics, and related conditions. An integrative hypothesis. Arch Gen Psychiatry 50: 306-317.

Klein DF, Skrobola AM, Garfinkel RS (1994). Preliminary look at the effects of pregnancy on the course of panic disorder. Anxiety 1: 227-232.

Kow LM (1976). Sensory requirements for the lordosis reflex in female rats. Brain Res 101: 47-66.

Loeppky JA, Scotto P, Charlton GC, Gates L, Icenogle M, Roach RC (2001). Ventilation is greater in women than men, but the increase during acute altitude hypoxia is the same. Respir Physiol 125: 225-237.

Martinez JM, Kent JM, Coplan JD, Browne ST, Papp LA, Sullivan GM et al (2001). Respiratory variability in panic disorder. Depress Anxiety 14: 232-237.

McCrimmon DR, Dekin MS, Mitchell GS (1995). Glutamate, GABA, and serotonin in ventilatory control. In: Dempsey JA (ed). Regulation of Breathing, 2nd edn. Marcel Dekker: New York. 
Modigh K, Westberg P, Eriksson E (1992). Superiority of clomipramine over imipramine in the treatment of panic disorder: a placebo-controlled trial. J Clin Psychopharmacol 12: 251-261.

Papp LA, Martinez JM, Klein DF, Coplan JD, Norman RG, Cole R et al (1997). Respiratory psychophysiology of panic disorder: three respiratory challenges in 98 subjects. Am J Psychiatry 154: 15571565.

Perna G, Bertani A, Caldirola D, Smeraldi E, Bellodi L (2001). A comparison of citalopram and paroxetine in the treatment of panic disorder: a randomized, single-blind study. Pharmacopsychiatry 34: 85-90.

Rapkin AJ, Pollack DB, Raleigh MJ, Stone B, McGuire MT (1995). Menstrual cycle and social behavior in vervet monkeys. Psychoneuroendocrinology 20: 289-297.

Rubinow DR, Schmidt PJ, Roca CA (1998). Estrogen-serotonin interactions: implications for affective regulation. Biol Psychiatry 44: 839-850.

Sasson Y, Iancu I, Fux M, Taub M, Dannon PN, Zohar J (1999). A double-blind crossover comparison of clomipramine and desipramine in the treatment of panic disorder. Eur Neuropsychopharmacol 9: 191-196.

Sodersten P, Eneroth P (1981). Serum levels of oestradiol-17 beta and progesterone in relation to sexual receptivity in intact and ovariectomized rats. J Endocrinol 89: 45-54.

Steiner M (1997). Premenstrual syndromes. Annu Rev Med 48: 447-455.

Steiner M, Katz RJ, Baldrighi G, Carroll BJ (1981). Motivated behavior and the estrous cycle in rats. Psychoneuroendocrinology 6: 81-90.

Steiner M, Steinberg S, Stewart D, Carter D, Berger C, Reid R et al (1995). Fluoxetine in the treatment of premenstrual dysphoria.
Canadian Fluoxetine/Premenstrual Dysphoria Collaborative Study Group. N Engl J Med 332: 1529-1534.

Sundblad C, Hedberg MA, Eriksson E (1993). Clomipramine administered during the luteal phase reduces the symptoms of premenstrual syndrome: a placebo-controlled trial. Neuropsychopharmacology 9: 133-145.

Sundblad C, Modigh K, Andersch B, Eriksson E (1992). Clomipramine effectively reduces premenstrual irritability and dysphoria: a placebo-controlled trial. Acta Psychiatr Scand 85: 39-47.

Swanson HH, van de Poll NE, van Pelt J (1982). Influence of the estrous cycle on heterosexual aggression in two strains of rats (S3 and WEzob). Horm Behav 16: 395-403.

Tatsumi K, Hannhart B, Moore LG (1995). Influences of sex steroids on ventilation and ventilatory control. In: Dempsey JA (ed). Regulation of Breathing, 2nd edn. Marcel Dekker: New York.

Villeponteaux VA, Lydiard RB, Laraia MT, Stuart GW, Ballenger JC (1992). The effects of pregnancy on preexisting panic disorder. $J$ Clin Psychiatry 53: 201-203.

Wikander I, Sundblad C, Andersch B, Dagnell I, Zylberstein D, Bengtsson $\mathrm{F}$ et al (1998). Citalopram in premenstrual dysphoria: is intermittent treatment during luteal phases more effective than continuous medication throughout the menstrual cycle? $J$ Clin Psychopharmacol 18: 390-398.

Yonkers KA (1997). Anxiety symptoms and anxiety disorders: how are they related to premenstrual disorders. J Clin Psychiatry 58: 62-67; discussion 68-69.

Yonkers KA, Zlotnick C, Allsworth J, Warshaw M, Shea T, Keller MB (1998). Is the course of panic disorder the same in women and men? Am J Psychiatry 155: 596-602. 